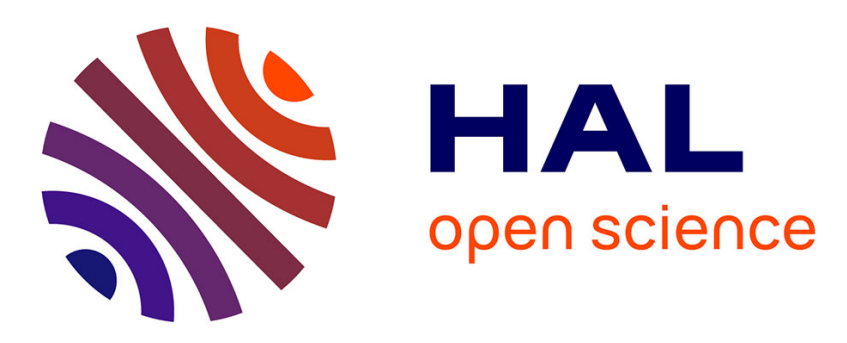

\title{
Meridional wind in the auroral thermosphere: Results from EISCAT and WINDII-O(1 D) coordinated measurements
}

\author{
Chantal Lathuillière, Jean Lilensten, W. Gault, Gérard Thuillier
}

\section{To cite this version:}

Chantal Lathuillière, Jean Lilensten, W. Gault, Gérard Thuillier. Meridional wind in the auroral thermosphere: Results from EISCAT and WINDII-O(1 D) coordinated measurements. Journal of Geophysical Research Space Physics, 1997, 102 (A3), pp.4487-4492. 10.1029/96JA03429 . hal-01628637

\section{HAL Id: hal-01628637 https://hal.science/hal-01628637}

Submitted on 13 Jan 2021

HAL is a multi-disciplinary open access archive for the deposit and dissemination of scientific research documents, whether they are published or not. The documents may come from teaching and research institutions in France or abroad, or from public or private research centers.
L'archive ouverte pluridisciplinaire HAL, est destinée au dépôt et à la diffusion de documents scientifiques de niveau recherche, publiés ou non, émanant des établissements d'enseignement et de recherche français ou étrangers, des laboratoires publics ou privés. 


\title{
Meridional wind in the auroral thermosphere: Results from EISCAT and WINDII-O $\left({ }^{1} D\right)$ coordinated measurements
}

\author{
C. Lathuillère and J. Lilensten
}

Centre d'Etude des Phénomènes Aléatoires et Géophysiques, Ecole Nationale Supérieure des Ingénieurs Electriciens de Grenoble, St Martin d'Hères, France

\author{
W. Gault \\ York University, Toronto, Canada
}

\section{G. Thuillier}

Service d'Aéronomie, Centre National de la Recherche Scientifique, Verrières le Buisson, France

\begin{abstract}
Neutral thermospheric winds calculated from European incoherent scatter (EISCAT) radar data have been compared with winds measured by wind imaging interferometer (WINDII) in $O\left({ }^{1} D\right)$ emission during 11 passes of the WINDII fields of view near the radar facility. For the eight occasions when geomagnetic activity was low the average difference in the meridional winds measured by the two methods is less than $10 \mathrm{~m} / \mathrm{s}$. The EISCAT calculations were done with and without a "Burnside factor" of 1.7 , and agreement with WINDII is somewhat better when the Burnside factor is not

included. The three passes corresponding to disturbed conditions show poor agreement. In addition, agreement between EISCAT and WINDII is better when unfiltered EISCAT winds are used, rather than the 2-hour running mean used in earlier work. This finding suggests that the short-term oscillations seen by EISCAT are real oscillations of the neutral atmosphere.
\end{abstract}

\section{Introduction}

Since the launch of the wind imaging interferometer (WINDII) on board the UARS on September 12, 1991, thermospheric winds and temperatures have regularly been measured at $F$-region altitudes by using the red line emission of atomic oxygen at $630 \mathrm{~nm}$. Below $230 \mathrm{~km}$ altitude, winds have also been measured by using the green line at $557 \mathrm{~nm}$. The meridional component of the thermospheric wind, on the other hand, can be derived from incoherent scatter radar measurements, allowing an intercomparison between the two sets of data.

The WINDII Michelson interferometer is described in detail by Shepherd et al. [1993a]. Its mission was to measure winds, temperatures, and emission rates in the altitude range 80 to $300 \mathrm{~km}$. Since the emphasis of WINDII measurements has been put on the lower thermosphere, most work up to now dealt with the green line observations [Shepherd et al., 1993b, 1995; McLandress et al., 1994; Bourg, 1995]. The validation of $\mathrm{O}\left({ }^{1} S\right)$ wind measurements [Gault et al., 1996; Thuillier et al., 1996] has shown that the WINDII zero wind reference in the altitude region 90$110 \mathrm{~km}$ agrees with external measurement methods within $10 \mathrm{~m} \mathrm{~s}^{-1}$. In addition, the thermospheric $O\left({ }^{1} S\right)$ meridional wind at $170 \mathrm{~km}$ altitude was in good agreement with European incoherent scatter (EISCAT) data. In the same

Copyright 1997 by the American Geophysical Union.

Paper number 96JAO3429

01 48-0227/97/96JA-03429\$09.00 work a zero wind calibration has been obtained for the $O\left({ }^{1} D\right)$ emission by comparison with $O\left({ }^{1} S\right)$ on several days when alternating $\left({ }^{1} D\right) /\left({ }^{1} S\right)$ measurements were made, but no comparisons have yet been done with external wind measurements.

The incoherent scatter technique can provide such external measurements. Indeed the ion velocity along the magnetic field line, which is directly measured by this method, is a balance between the projections of the neutral wind (vertical and meridional components) and the vertical ambipolar diffusion velocity. The method that we have used to calculate the meridional neutral component from EISCAT observations is described by Lilensten and Lathuillere [1995]. Comparisons of EISCAT-derived meridional wind and measurements with the Michelson interferometer for coordinated auroral Doppler observations (MICADO) described by Thuillier and Hersé [1991] had showed good agreement on a timescale of 2 hours [Lilensten et al., 1992]. By using a running average of 2 hours a very good agreement between EISCAT meridional wind calculated during two long campaigns (5 and 2 days) and the model of Fauliot et al. [1993] has also been found.

In the first part of this paper we show 11 profiles of WINDII meridional winds obtained during coordinated EISCAT-WINDII measurements, as well as the result of the calculation of this wind from EISCAT data, with or without the so-called "Burnside factor" [Salah, 1993] in the ionneutral collision frequency.

In the second part we use only the eight profiles obtained during very quiet conditions to calculate a mean difference between the two sets of data. Results will be discussed in terms of the validation of WINDII ${ }^{1}(D)$ winds and the 
Burnside factor. In addition, temporal variations of EISCAT-derived meridional winds will be discussed.

\section{Meridional Winds During EISCAT- WINDII Coordinated Measurements}

Between October 1992 and March 1994, French EISCAT campaigns were organized for times when the WINDII fields of view were above Tromso. Typically, one could get two to three WINDII passes, temporally spaced by about 1 hour $30 \mathrm{~min}$, in the vicinity of the EISCAT radar on the same day. Including the EISCAT common program experiments, when it happens that WINDII was looking at the red line above EISCAT, we find 6 days available for our study in our database, giving 11 passes. Twilight WINDII data have been disregarded, as well as EISCAT data, which did not provide ion velocity measurements along the magnetic field line with a temporal resolution at least of the order of the time-interval between the passes of the two WINDII fields of view above the same point, i.e., about 8 min. In practice we kept only CP1 type data (Tromso antenna is maintained field aligned), integrated over $5 \mathrm{~min}$ or $1 \mathrm{~min}$, and CP2 data (Tromso antenna is doing a fourposition cycle in $6 \mathrm{~min}$ ), integrated for about $1 \mathrm{~min}$. Our definition of a coordinated measurement corresponds to a ground range from Tromso to the midpoint of the region observed by WINDII smaller than $300 \mathrm{~km}$, i.e., smaller than the WINDII field of view ground coverage.

Table 1 shows the UT time of the WINDII wind altitude profile above Tromso for each of these 6 days. It corresponds to the mean time between the two field of view overpasses. In each case we have chosen the EISCAT data at the closest time available. The magnetic index $A p$ is also provided in the table, as well as the electric field value measured by EISCAT at the times of WINDII passes. One can see that 2 days, August, 5, 1992 and February, 17, 1993, are active days but only three profiles (referenced by a letter in the table and in the following figures) locally correspond to periods of large electric fields. For the eight other wind profiles (referenced by a number) the magnetic local conditions were extremely quiet with electric field amplitudes smaller than $8 \mathrm{mV} / \mathrm{m}$.

\subsection{EISCAT-Derived Meridional Winds}

Figure 1 shows as a solid line the meridional wind Un calculated from EISCAT data for each of the WINDII overpasses:

$$
\mathrm{Un}=-\mathrm{Vi} / \cos \mathrm{I}+\mathrm{Vdiff} \tan \mathrm{I}+\mathrm{Uz} \tan \mathrm{I}
$$

where $\mathrm{Vi}$ is the parallel ion velocity, Vdiff is the diffusion velocity, $\mathrm{Uz}$ is the vertical neutral wind, and $\mathrm{I}$ is the magnetic dip angle ( $I=68.6^{\circ}$ for our data). Given the small declination angle of the magnetic field line over EISCAT (less than $1^{\circ}$ in the thermosphere), this wind calculated in the magnetic meridian is closely equivalent to that obtained in the geographic north-south direction from WINDII.

The dashed line shows the contribution of the ion velocity (-Vi / cosI ), and the dashed-dotted line shows the contribution of the diffusion velocity (-Vdiff $\tan$ I). It has been assumed that the vertical neutral wind was zero. As one can see in Figure 1, the diffusion velocity plays a major role with amplitudes at $250 \mathrm{~km}$ altitude ranging between about $30 \mathrm{~m} / \mathrm{s}$ (profile A) and $100 \mathrm{~m} / \mathrm{s}$ (profile 3). It is consequently important to point out here the main uncertainties in its calculation. The altitude variation of Vdiff is mainly due to the gradients of the electron density: for example one can compare profiles obtained on August,

Table 1. WINDII - EISCAT Correlative Experiments

\begin{tabular}{|c|c|c|c|c|c|}
\hline Date & UARS Day & $A p$ & $\begin{array}{c}\text { UT Time of Tromso } \\
\text { Overpass }\end{array}$ & $\begin{array}{l}\text { Electric Field, } \\
\qquad \mathrm{mV} / \mathrm{m}\end{array}$ & Reference \\
\hline \multirow[t]{3}{*}{ Aug. 5, 1992} & 329 & 35 & $6.70^{*}$ & $24.4^{*}$ & $A^{*}$ \\
\hline & & & 8.33 & 1.1 & 1 \\
\hline & & & 9.98 & 7.4 & 2 \\
\hline Oct. 28,1992 & 413 & 19 & 6.19 & 6.9 & 3 \\
\hline \multirow[t]{2}{*}{ Feb. 17, 1993} & 525 & 36 & $12.90^{*}$ & $46 *$ & $\mathrm{~B}^{*}$ \\
\hline & & & $14.54^{*}$ & $98.3^{*}$ & $\mathrm{C}^{*}$ \\
\hline July 21, 1993 & 679 & 8 & 11.98 & 6.3 & 4 \\
\hline \multirow[t]{2}{*}{ March 1, 1994} & 902 & 12 & 9.06 & 2.2 & 5 \\
\hline & & & 10.70 & 3.1 & 6 \\
\hline \multirow[t]{2}{*}{ March 2, 1994} & 903 & 20 & 9.12 & 0.6 & 7 \\
\hline & & & 10.76 & 3.8 & 8 \\
\hline
\end{tabular}

\footnotetext{
* disturbed conditions
} 

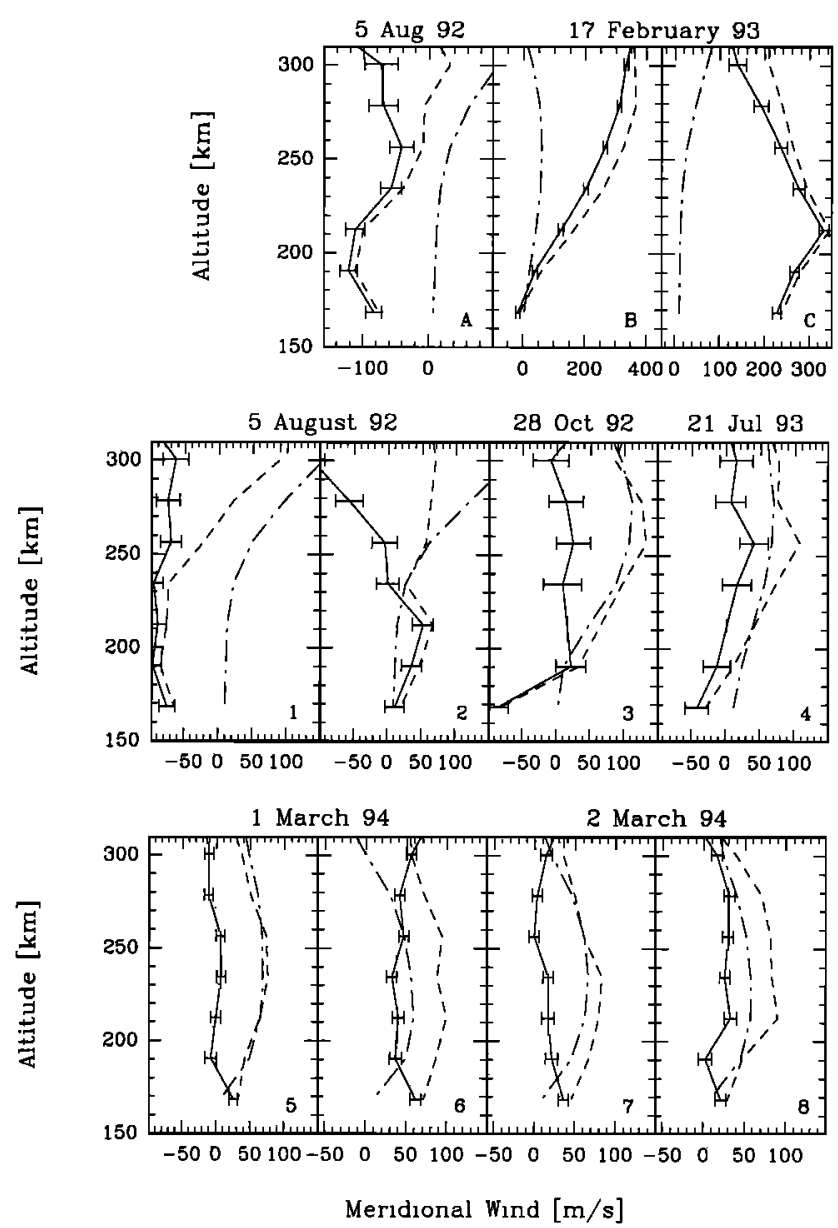

Figure 1. Profiles of the EISCAT calculated meridional winds (solid line), which correspond to the differences between the projection of the measured ion velocity (dashed line) and the projection of the diffusion velocity (dasheddotted line). The Burnside factor has not been used here. The letters and numbers refer to Table 1 .

5, 1992 (profiles 1 and 2), for which the maximum electron density occurs above $320 \mathrm{~km}$ altitude, with profiles obtained in March 1994 (profiles 4 to 8), when the maximum of the $F$ layer is around $250 \mathrm{~km}$.

The amplitude of Vdiff is inversely proportional to the ion-neutral collision frequency, which at the altitudes that we consider is primarily the $\mathrm{O}^{+} \mathrm{O}$ collision frequency (see Lilensten and Lathuillere [1995] for the explicit formulation of the ambipolar diffusion velocity that we have used here). The neutral densities used in collision frequency calculations have been obtained from the MSIS-90 model for the given date and time, with the $A p$ indices of Table 1 and an exospheric temperature equal to the measured ion temperature at $280 \mathrm{~km}$ altitude. This procedure may overestimate the neutral temperature in the case of Joule heating and consequently overestimate the neutral densities. That is why the exospheric temperature has in addition been limited to $1200 \mathrm{~K}$. Furthermore, we have used two different formulations of the $\mathrm{O}^{+} \mathrm{O}$ collision frequency: (1) the value proposed by Salah [1993] as a recommended interim consensus standard value, which includes the so-called Burnside factor of 1.7 proposed to reconcile the ground interferometer data and the radar data [Burnside et al., 1987], and (2) the same value without this 1.7 factor.

The diffusion velocity shown in Figure 1 corresponds to the second value, i.e., without the Burnside factor. It emphasizes the importance of the contribution of the diffusion velocity in the calculation of the meridional wind. Using the Burnside factor will reduce the diffusion velocity by a factor of 1.7 .

\subsection{Comparison of WINDII and EISCAT Winds}

In Figure 2 we show in solid lines the meridional wind measured by WINDII. These values use the zero wind reference described by Gault et al. [1996].

Results of EISCAT calculations are shown as dasheddotted lines when the Burnside factor is included in the $\mathrm{O}^{+} \mathrm{O}$ collision frequency and as dotted lines when the Burnside factor is not used. The error bars have not been plotted in this figure for more clarity, but they are given in Figure 1. Two different behaviors are clearly seen in Figure 2: for the first three profiles referenced by a letter there is obviously little agreement between the two instruments. The EISCATWINDII wind differences are of the order of $100 \mathrm{~m} / \mathrm{s}$. As was noted above, these three profiles correspond to active periods according to the electric field values of Table 1. Under these conditions our assumption of zero vertical
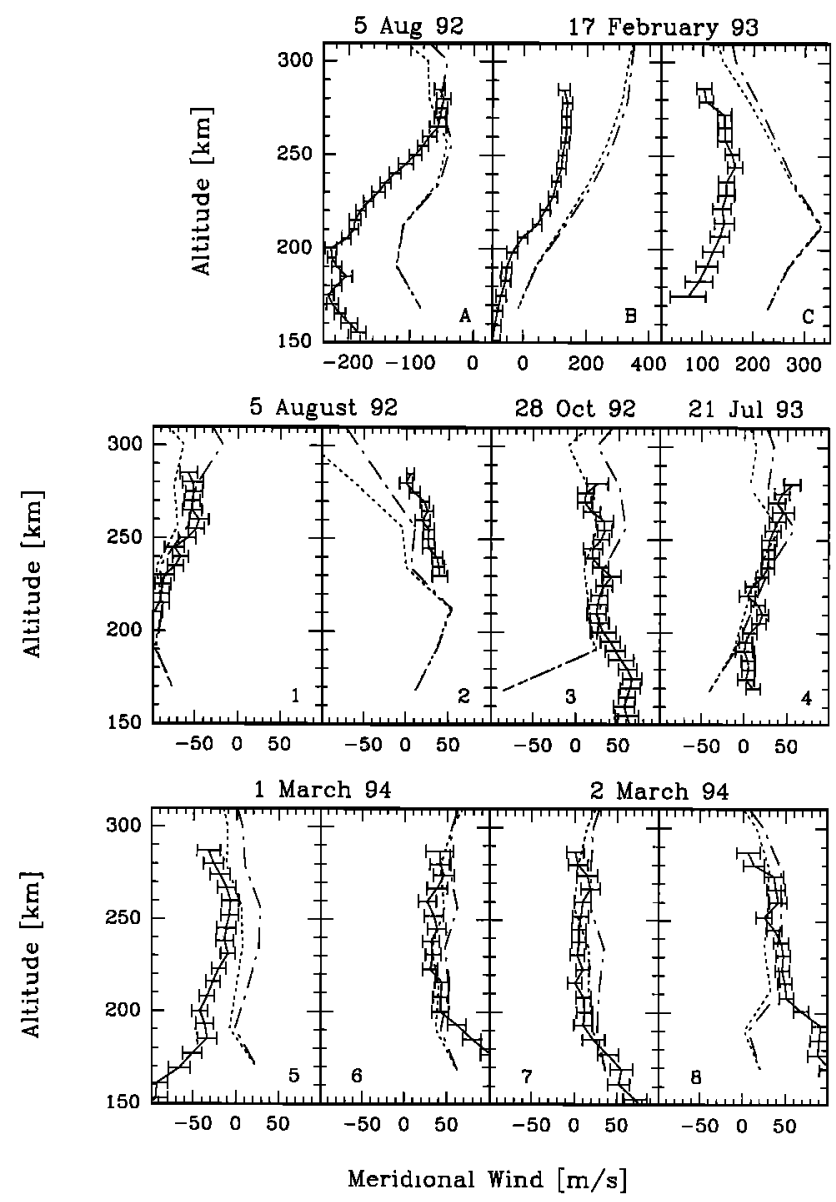

Figure 2. Comparison of the meridional wind profiles measured by WINDII (solid line) and those calculated by EISCAT. The dashed-dotted line is obtained when the Burnside factor is included in the $\mathrm{O}^{+} \mathrm{O}$ collision frequency, and the dashed line is obtained when it is not included. 
winds is certainly not valid. Because of the factor tan $I$ in equation (1) a vertical upward wind of about $25 \mathrm{~m} / \mathrm{s}$ could explain the differences. Much larger vertical neutral winds have already been observed in auroral zones during active periods. Indeed, Fauliot et al. [1993] have been able to give an empirical formulation to relate the vertical wind measured by the MICADO instrument to the local variation of the magnetic field.

Vertical winds, however, are not the only problem in EISCAT calculations. These periods also correspond to strong Joule heating: neutral temperature and densities may be quite different from the one obtained from MSIS- 90 .

On the other hand, WINDII apparent quantities have been inverted under the assumption of a locally spherically isotropic and time invariant atmosphere [Gault et al., 1996]. It is likely that in the cases of large gradients, as can be found in the auroral thermosphere, the result of the inversion will represent a mean value along the WINDII line of sight. In such cases it might be more appropriate to use tomographic methods with constraints to invert the WINDII data, methods that would take into account a latitudinal variation of the winds along the line of sight. Such a variation is already present in the corresponding zonal winds observed by WINDII on February 17 (not shown here) that are of the order of $-600 \mathrm{~m} / \mathrm{s}$ over the latitudinal range $60^{\circ}$ to $70^{\circ}$.

The eight profiles referenced by a number have been plotted with the same scale. For them the overall agreement is very good. Only profile 2 displays a clear difference between the two instruments for both calculations of the diffusion velocity. One can also observe that the good agreement usually breaks down at the lowest altitude of EISCAT measurements, i.e., $168.5 \mathrm{~km}$. At this altitude the contribution of the diffusion velocity is very small: indeed, the mean difference between the meridional wind measured by WINDII with the green line and the EISCAT-calculated wind, neglecting the diffusion velocity, was less than $5 \mathrm{~m} / \mathrm{s}$ [Gault et al., 1996]. On the other hand the $\mathrm{O}\left({ }^{1} D\right)$ emission
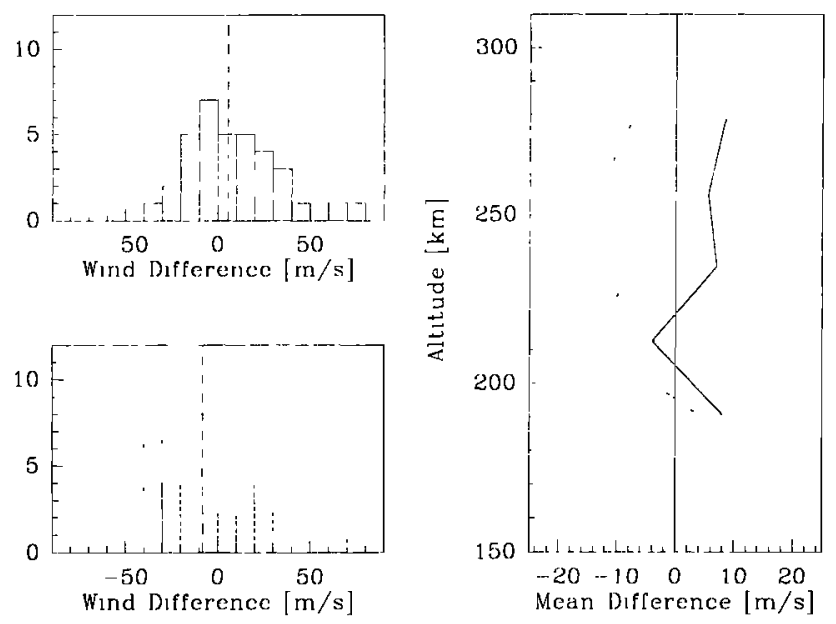

Mean Difference $[\mathrm{m} / \mathrm{s}]$

Figure 3. Histograms of (left) the differences between WINDII and EISCAT meridional winds and (right) mean differences as a function of altitude. The upper left panel and the solid line correspond to EISCAT-calculated winds that do not include the Burnside factor. The lower left panel and the dashed line correspond to EISCAT-calculated winds that include the Burnside factor. is much weaker at this altitude than above, and measured winds may be more sensitive to the inversion method used. More work is necessary to understand these differences.

Looking more carefully at the eight profiles, we generally find a better agreement between WINDII winds and the EISCAT-calculated ones when the Burnside factor is not used. This is not the case for the two profiles of August 5, 1992 (profiles 1 and 2). These two profiles correspond to a quiet period that just follows an active one (see Table 1). Indeed the ion velocity diffusion does not show a maximum because of a particularly high $F$ layer. It is likely that perturbations of neutral densities are still present at these times, making it very difficult to obtain a correct estimate of the diffusion velocity.

\section{Discussion}

The WINDII meridional winds have been interpolated at the altitudes of EISCAT observations excluding the lowest one, and wind differences have been calculated (WINDII wind versus EISCAT wind). Histograms of these differences are presented in the two left panels of Figure 3. One shows the wind differences when the diffusion velocity is calculated without the Burnside factor (upper panel), and the other shows them with the Burnside factor (lower panel). The mean values are $+5.5 \mathrm{~m} / \mathrm{s}$ and $-8 \mathrm{~m} / \mathrm{s}$, respectively, and the standard deviation is $18.6 \mathrm{~m} / \mathrm{s}$ and 21.6 $\mathrm{m} / \mathrm{s}$. The panel on the right shows the mean differences as a function of the altitude with values greater than 2 sigma removed. At $190 \mathrm{~km}$ altitude, both values are positive and close to each other because the diffusion velocity is very small. These values are close to the mean difference that has previously been found between EISCAT and $O\left({ }^{1} S\right)$ meridional winds, as noted in the previous section. At higher altitudes there is a consistent positive bias between WINDII and EISCAT if the Burnside factor is not used and a negative one in the other case.

Whatever the choice of the ion - collision frequency values, our comparisons allow us to conclude that the EISCAT measurements confirm the WINDII zero wind reference for the $O\left({ }^{1} D\right)$ emission within $10 \mathrm{~m} / \mathrm{s}$. This was also the conclusion of the validation of $O\left({ }^{1} S\right)$ winds against external measurements [Gault et al., 1996].

Can we make any conclusive statement about the value of the Burnside factor?

First, our aim here was not to try to obtain this factor, as was done in previous work. This process would require more coordinated measurements to obtain meaningful statistics and a more precise WINDII zero wind calibration validated against more external measurements.

Nevertheless, several arguments make us think that our EISCAT-derived winds are in better agreement with WINDII measurements when the Burnside factor is not included in the $\mathrm{O}^{+} \mathrm{O}$ collision frequency: (1) Figure 2 shows that there were more profiles in good agreement in this case; (2) the form of the histogram of the WINDII-EISCAT differences (Figure 3) is closer to a Gaussian; and (3) the mean wind difference is slightly positive (Figure 3 ), as were most of the wind differences found between $O\left({ }^{1} S\right)$ WINDII winds and external measurements [Gault et al., 1996].

In Figure 4 we show examples of the time variations of the EISCAT meridional winds at 256 or $234 \mathrm{~km}$ altitude, calculated without the Burnside factor, for the five quiet 

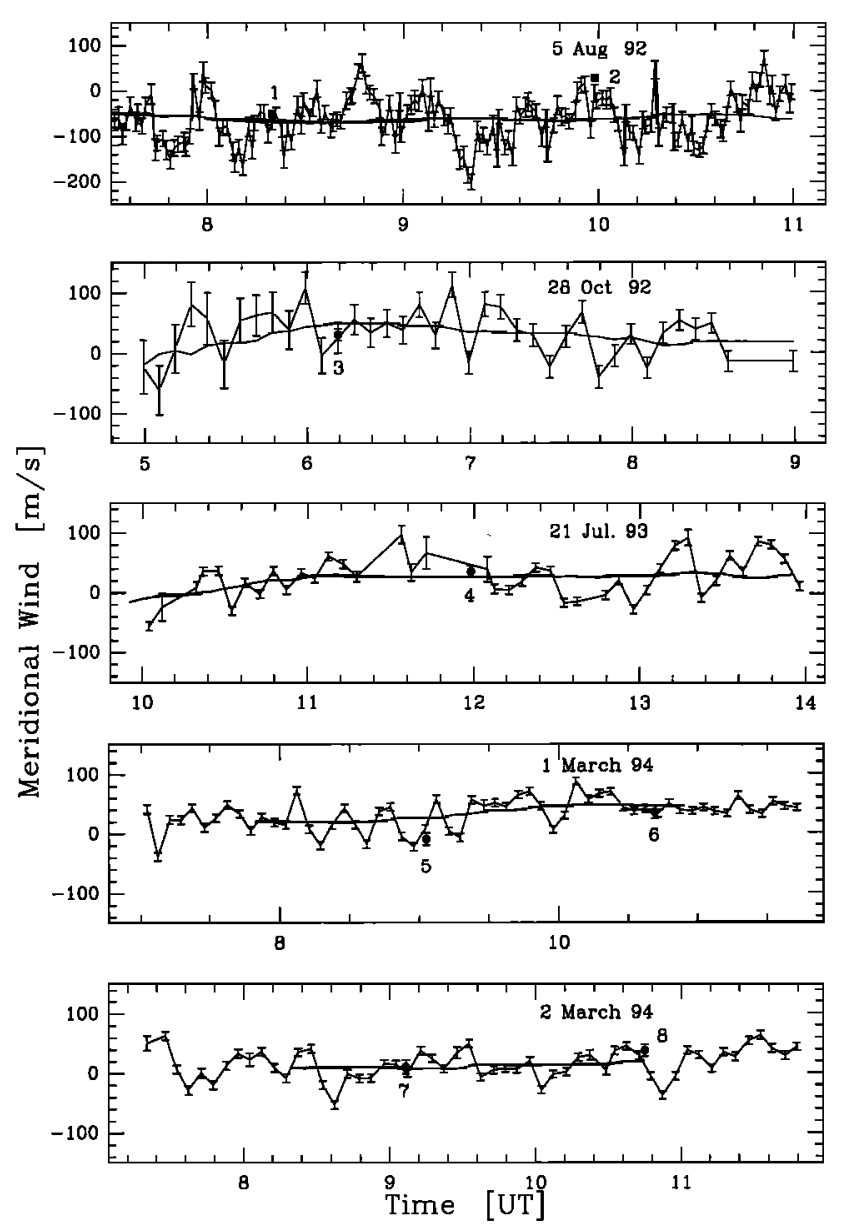

Figure 4. Time variations of the EISCAT meridional wind for the quiet periods at $234 \mathrm{~km}$ altitude (March 1, 1994) or $256 \mathrm{~km}$ ( 4 other days). The smooth line is a 2-hour running average. The WINDII wind values are superimposed and marked by the reference numbers of Table 1 .

periods, on which the WINDII winds are superimposed. The numbers indicated on each panel are the profile reference numbers from Table 1 . When the EISCAT integration time was $5 \mathrm{~min}$ (three lower panels), the EISCAT timescale was shifted by $+2.5 \mathrm{~min}$, in order to attribute the EISCAT wind to the mean time of the integration period. The WINDII time corresponds to the mean value between two very short measurements taken 8 min apart. This comparison is the best one that can be achieved in terms of temporal resolution for our two sets of data. The smooth line superimposed on each panel is a 2 hour running average of the EISCAT winds. One can see that the WINDII winds agree with the $1 \mathrm{~min}$ or $5 \mathrm{~min}$ integrated EISCAT winds in all the experiments and disagree with the means when they are far from the instantaneous measurements (point 2 on August 5 and 5 on March 1). More examples exist at different altitudes, but it does not seem necessary to show them as graphs.

Indeed we have first tried to make the comparison between WINDII data and EISCAT profiles averaged over 2 hours. This was done in order to damp down the observed oscillations in EISCAT data. The agreement was worse, as can be seen in the two examples shown in Figure 4.

\section{Conclusion}

We have here shown the first comparison between altitude profiles of meridional winds obtained by two completely different methods. The excellent agreement found in the case of quiet local magnetic conditions gives us confidence that both data sets are correct within $10 \mathrm{~m} / \mathrm{s}$.

When electric fields are present in the ionosphere, large discrepancies are found; these can be explained by the intrinsic limitations of the two techniques used to obtain meridional wind measurements.

We have found that our two sets of data were in better agreement when the Burnside factor was not included in the $\mathrm{O}^{+} \mathrm{O}$ collision frequency calculation. However, as we have pointed out, this result has to be validated by using other data. This can be done by using the midlatitude and lowlatitude incoherent scatter radar data that are correlated to WINDII $O\left({ }^{1} D\right)$ measurements.

Finally, we have found a better agreement between EISCAT and WINDII wind profiles without any temporal averaging of data, suggesting that the oscillations found in the EISCAT-calculated meridional winds are real oscillations of the neutral atmosphere that are present even in the case of very low magnetic activity.

Acknowledgements. The WINDII project is sponsored by the Canadian Space Agency and the Centre National d'Etudes Spatiales. EISCAT correlative investigations have been supported by the Centre National de la Recherche Scientifique (program PAMOY). The EISCAT facility is supported by the research councils of Finland (SA), France (CNRS), the Federal Republic of Germany (MPG), Norway (NAVF), Sweden (NFR) and the United Kingdom (SERC). Part of the calculation have been made in the Centre de Calcul Intensif de l'Observatoire de Grenoble.

The editor thanks Joseph E. Salah and another referee for their assistance in evaluating this paper.

\section{References}

Bourg, L., Contribution à l'étude de la dynamique de la mésosphère: Interprétation des mesures de l'interféromètre WINDII placé à bord du satellite UARS, thèse de doctorat, Univ. Paris 7, 1995.

Burnside, R.G., C.A. Tepley, and V.B. Wickwar, The O+-O collision cross section: Can it be inferred from aeronomical measurements?, Ann. Geophys., Ser.5A., 343-350, 1987.

Fauliot, V., G. Thuillier, and M. Hersé, Observation of the $F$ region horizontal and vertical winds in the auroral zone, Ann. Geophys., 11, 17-28, 1993.

Gault W.A., et al., Validation of $O\left({ }^{1} S\right)$ wind measurements by WINDII: The wind imaging interferometer on UARS, $J$. Geophys. Res., 101, 10, 405-10, 430, 1996.

Lilensten, J., and C. Lathuillere, The meridional thermospheric neutral wind measured by the EISCAT radar, J. Geomagn. Geoelectr., 47, 911-920, 1995.

Lilensten, J., G. Thuillier, C. Lathuillère, W. Kofman, V. Fauliot, and M. Herse, EISCAT-MICADO coordinated measurements of meridional wind, Ann. Geophys., 10, 603-618, 1992.

McLandress, C., Y. Rochon, G.G. Shepherd, B.H. Solheim, G. Thuillier, and F. Vial, The meridional wind component of the thermospheric tide observed by WINDII on UARS, Geophys. Res. Lett., 21, 2417-2420, 1994

Salah, J.E., Interim standard for the ion-neutral atomic oxygen collision frequency, Geophys. Res. Lett., 20, 1543-1546, 1993.

Shepherd, G.G., et al., WINDII: The wind imaging interferometer on the Upper Atmosphere Research Satellite, J. Geophys. Res., 98, 10,725-10,750, 1993a.

Shepherd G.G., et al., Longitudinal structure in atomic oxygen concentration observed with WINDII on UARS, Geophys. Res. Lett., 20, 1303-1306, 1993b.

Shepherd, G.G., C. McLandress, and B.H. Solheim, Tidal 
influence on $O\left({ }^{1} S\right)$ airglow emission rate distributions at the geographic equator as observed by WINDII, Geophys. Res. Lett., 22, 275-278, 1995.

Thuillier, G., and M. Hersé, Thermally stable field compensated Michelson interferometer for measurement of temperature and wind of the planetary atmospheres, Appl. Opt., 30, 1210-1220, 1991.

Thuillier, G., V. Fauliot, M. Hersé, L. Bourg, and G.G. Shepherd, The MICADO wind measurements from Observatoire de Haute-Provence for the validation of the WINDII green line data, J. Geophys. Res., 101, 10, 431-10, 440, 1996.

W. Gault, York University, Toronto, Ontario, Canada, M3J1P3.
C. Lathuillère and J. Lilensten, Centre d'Etudes des Phénomènes Aléatoires et Géophysiques, Ecole Nationale Superieure des Ingénieurs Electriciens de Grenoble, B. P. 46, 38402 St Martin d'Hères, France.(e-mail: chantal@cephag.observgr.fr)

G. Thuillier, Service d'Aéronomie, Centre National de la Recherche Scientifique, B. P. 91371 Verrières le Buisson, France

(Received June 3, 1996; revised October 21, 1996; accepted October 26, 1996.) 